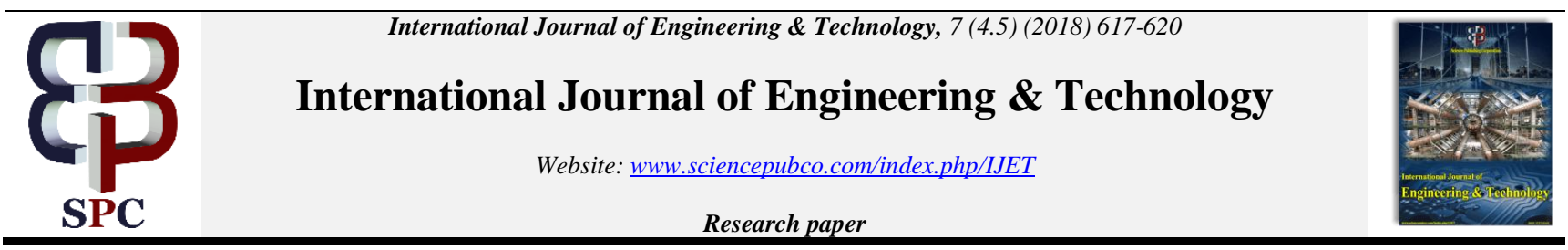

\title{
Steel plate shear wall - a 20th century review
}

\author{
Sudarshan R. Vhatkar ${ }^{1}$, Pradip D. Jadhao ${ }^{2}$ \\ ${ }^{1}$ Research Scholar, Department of Civil Engineering, K. K. Wagh Institute of Engineering Education and Research, Hirabai Haridas \\ Vidyanagari, Amrutdham, Panchayat, Nashik. Affiliated to Savitribai Phule Pune University, Pune. (Maharashtra State). India. \\ P.I.N.422003 \\ ${ }^{2}$ Professor and Head, Department of Civil Engineering, K. K. Wagh Institute of Engineering Education and Research, Hirabai \\ Haridas Vidyanagari, Amrutdham, Panchavati, Nashik. Affiliated to Savitribai Phule Pune University, Pune. (Maharashtra State). \\ India. P.I.N.422003 \\ *Corresponding author E-mail: srvhatkar@kkwagh.edu.in
}

\begin{abstract}
This paper provides a brief summary carried out in past analytical and experimental research work on steel plate shear walls with emphasis given up to 20th Century. In buildings, two different systems exist to resists the loads viz., gravity load system and a lateral load system. To transfer the vertical loads to the footing gravity load system is used while lateral loads due to wind and seismic loads are resisted by the Lateral Load Resisting System (LLRS). Steel Plate Shear Walls (SPSW) is relatively a new type of LLRS; it has many distinct performance benefits including large displacement ductility capacities, high elastic stiffness properties, and stable hysteresis behavior as compared to other LLRS. The experimental results were also compared with simplified analytical models. The capacity of SPSW is limited to elastic buckling strength of its plate panels. This practice results not only in an undesirable one, but also in a conservative design, where columns buckle and may yield before the plate reaches a fraction of its capacity. With failure plate buckling is not synonymous and along its boundaries if plate is supported adequately, as in the case of SPSW the post buckling strength may be several times theoret- ical buckling strength.
\end{abstract}

Keywords: Diagonal Tension Field; Horizontal Boundary Element; Lateral Load Resisting System; Steel Plate Shear Wall; Vertical Boundary Element.

\section{Introduction}

In building structures, normally loads are resisted by two different systems; viz., a gravity force system and a lateral force system. The gravity force system is used to transfer vertical loads to the foundation, while the lateral force, wind and seismic loads are resisted by the Lateral Load Resisting System (LLRS).

Now - a - days, different types of LLRS have with structural engineers to choose from. Each building structure is different and many factors come into effect while selecting the best suitable LLRS. SPSW are often considered effective for LLRS including mid - rise to high - rise structures. SPSW may be used as a main LLRS or as a secondary LLRS often replacing typical concrete shear wall core in high - rise structures. The SPSW system has been used since the 1970 s, with the systems popularity growing slowly over the past few decades.

The SPSW consists of steel - frame, which may have either rigid or flexible beam - to - column connections, with steel infill web plates connected to the beams and columns as shown in Fig. 3. The horizontal beams are commonly referred to as Horizontal Boundary Elements (HBEs) and the vertical columns are com- monly referred to as Vertical Boundary Elements (VBEs). Fig. 5 shows typical Steel Plate Shear Wall (SPSW) with its nomencla- ture. SPSW are lighter and more ductile than the reinforced ce- ment concrete shear walls. An increase in the erection speed and usable space are realized often.

In several countries around the world the supporting theory has evolved from both analytical and experimental research conducted. The steel infill panels are allowed to buckle in shear and form a diagonal tension field subsequently. A major failure mode of typical SPSW is as shown in Fig. 7.

\section{An overview}

In 1993, M. Elgaaly et al, have described analytical models. With a reasonable assumption for thin plates, a simple model was developed based on ignoring the strength of pre - buckling of the plate panels. The models consist of replacing the plate panels by the diagonal tension members. By assuming the stress - strain relationship for these members to be bi - linearly elastic perfectly plastic. Using the test results the characteristics of the stress - strain relationship were determined empirically. For three speci- mens the models were able to predict the test behaviour very accu- rately. Fig. 1 shows analytical cyclic strip model for SPSW specimen with pull and push direction [4]. 


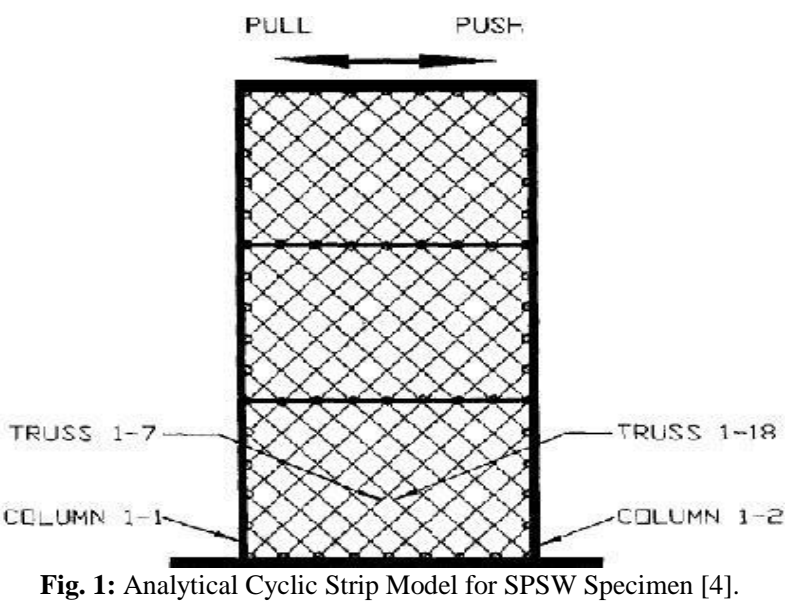

The strain e0, which is used in the analytical model, can be determined from (1) given below,

$\mathrm{e} 0=\mathrm{K} 1 \times \mathrm{e} 1$

Where, $\mathrm{K} 1=$ an empirical factor to be determined from the test results and it is less than 1.0 .

The corresponding stress $\sigma 0$ can be determined from (2) given below,

$\sigma_{0}=\mathrm{K}_{2} \times \mathrm{e}_{0} \times \mathrm{E}_{1}$

\section{Where,}

$\mathrm{K} 2$ = another empirical factor that can be determined from

The test results and it is less than 0.5 [4].

Again in 1993, Vincent Caccese et al, presents an investigation into the seismic behavior results of un - stiffened thin steel - plate shear walls. To resist seismic forces effective use of thin steel - plate shear walls is possible. By addition of a un - stiffened thin steel plate to a steel frame gives a substantial increase in energy adsorption, stiffness, and load carrying capacity, of a system. The system strength is governed by the plastic hinge formation in the columns, inelastic behavior commences by yielding of the plate when a slender plate is used. Fig. 2 shows the test set with reaction frame, upper guide, actuator, lateral bracing specimen, $\mathrm{X}$ - brac- ing [9].
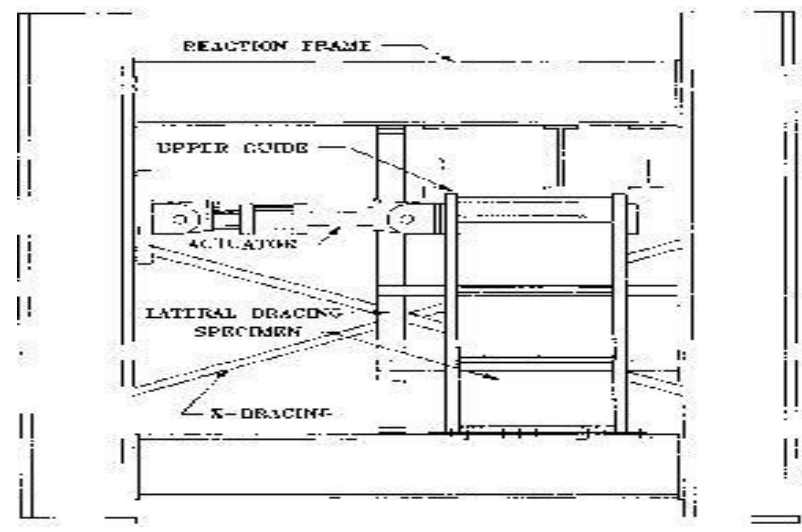

Fig. 2: Test Setup [9]

In 1996, R. G. Driveret al, have tested a four - storey, single bay specimen, to determine its behavior under an idealized severe earthquake event, fabricated using industry - standard details and methods. The specimen endured 30 cycles of loading, including 20 cycles in the inelastic range during the tests. In 22 cycles the maximum load capacity was reached, after that the deterioration was very gradual and stable. During each of the remaining cycles of increasing deformations the load - carrying capacity of the test specimen declined very gradually. The behavior of the specimen and the manner in which the damage to the shear wall eventually developed in the study. Fig. 3 shows a typical actual SPSW [6]

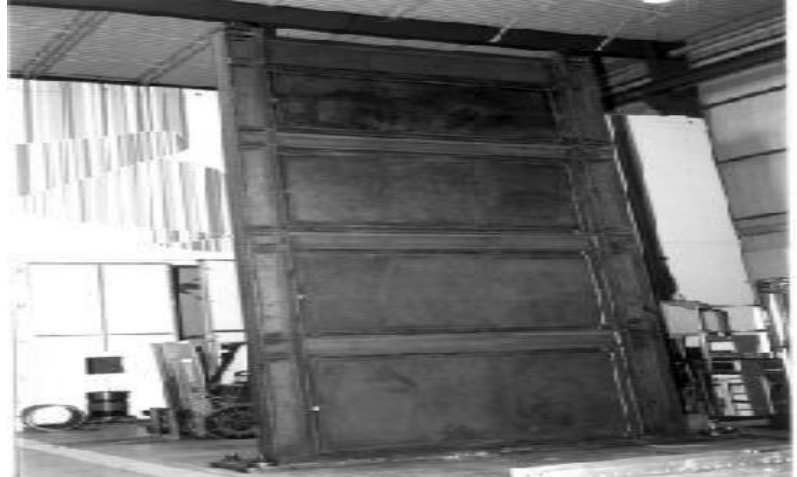

Fig. 3: Typical Steel Plate Shear Wall [6]

In 1997, Mohamed Elgaaly et al, have concluded that the behavior of thin - steel - plate shear walls is governed only by the tension field action and also controlled by the boundary conditions. Using the equivalent truss elements is able to depict the test results to a good accuracy by the analytical models. The columns attached to the walls have to be designed such that they will not buckle or yield before the plate develops its full capacity by yielding of the diagonal tension field has to be noted. Using a strip - gusset element the load - elongation characteristic was derived [3].

In 1998, R. G. Driver et al, have tested a four - storey, single bay steel plate shear wall with beam - to - column moment - resisting connections under an idealized earthquake - type loading. A un stiffened steel infill plate was used. Cyclic in - plane horizontal loads were applied at each floor level and gravity loads of constant magnitude were applied to each column. Corresponding to significant yield was reached, the capacity of the test specimen increased until a deflection of five times the deflection, after which degradation was stable and slow. Fig. 4 gives North elevation of SPSW test specimen [7].

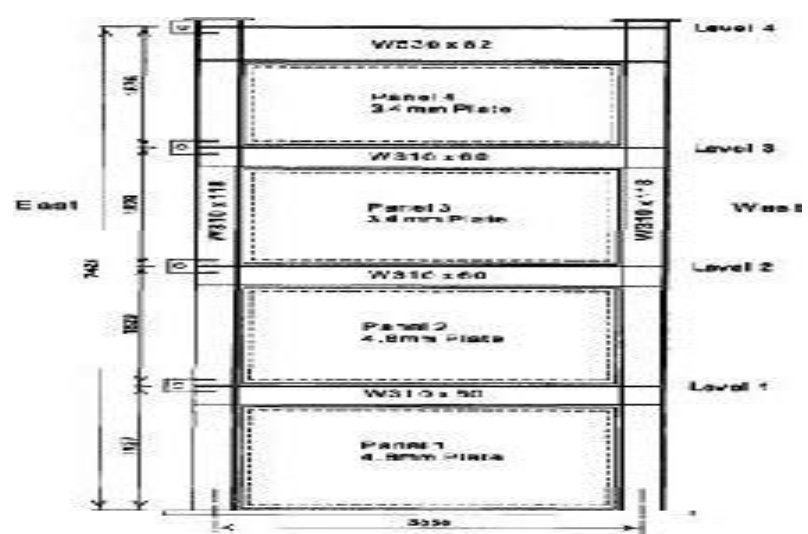

Fig. 4: SPSW Test Specimen (North Elevation) [7]

Again in 1998, Robert G. Driver et al, have developed a nonlinear finite - element model for steel plate shear walls and then tested four - story test specimen using the as - built dimensions and measured material properties of a large - scale. It gave an excel- lent prediction of the load versus deflection response when in the model non - planar initial plate geometry and measured residual stresses were included. For the prediction of monotonic behavior, another analytical method was studied. The models account for Inelastic behavior in both the frame members and the infill panels. Fig. 5 shows the pin ended tension strip [5]. 


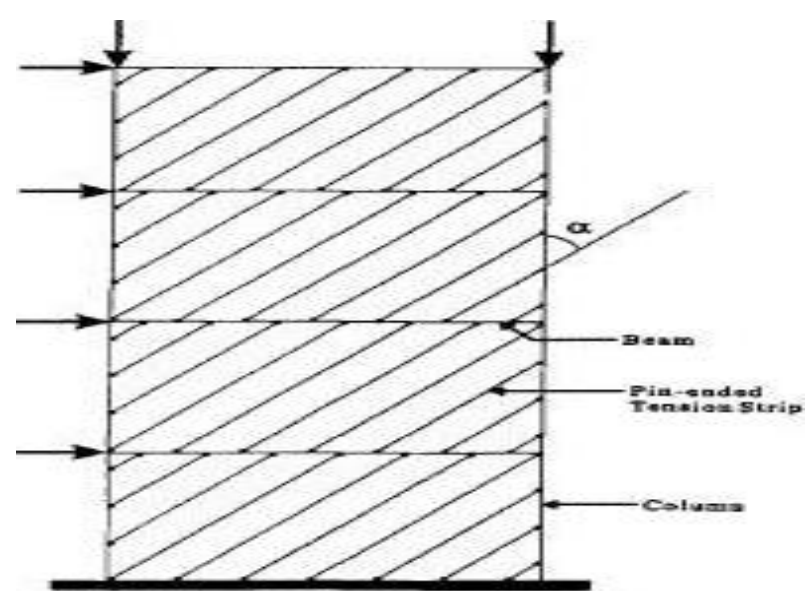

Fig. 5: Plane Frame Strip Model of Test Specimen [5].

In 2000, A. Astaneh - ASL, have concluded that the steel walls can be used within a simply supported frame or can be part of a dual system. In dual system, the entire moment frame after steel plate is removed can be considered the backup system and the shear wall and its boundary elements are the primary lateral load - resisting system. In a consequential failure mode the slippage of the boundary bolts should not be considered. In fact, a mechanism of energy dissipation through friction and introduces some benefi- cial "semi - rigidity" to the structure is provided due to such slip- page. On actual cyclic behavior and analytical modeling, consid- erable amount of research is conducted on SPSW. Fig. 6 gives the details of test set - up [1].

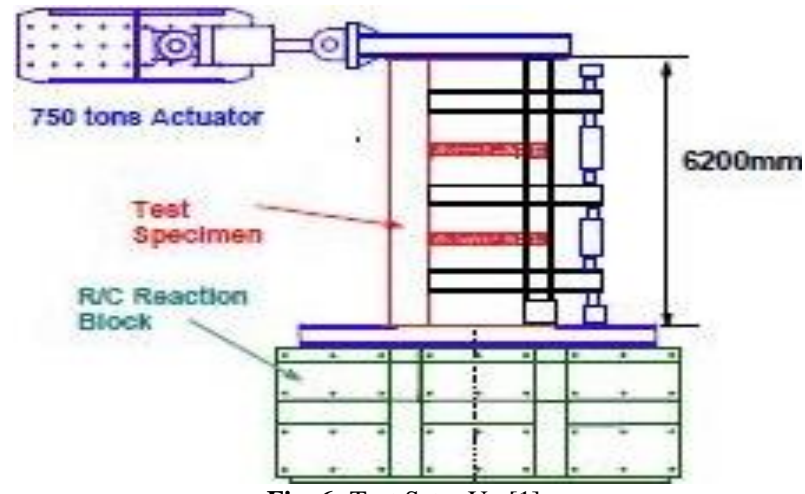

Fig. 6: Test Set - Up [1]

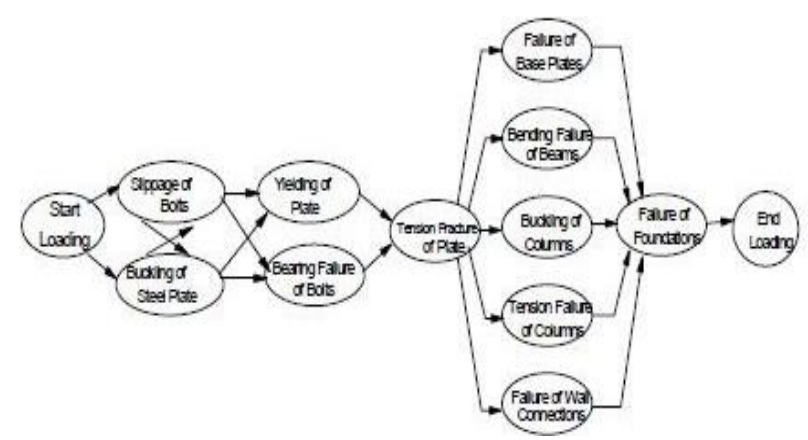

Fig. 7: Major Failure Modes of Typical Steel Plate Shear Walls [1].

Also in 2000, S Sabouri - Ghomi, with Roberts a theoretical model for predicting the hysteretic characteristics of un - stiffened steel plate shear panels, has been developed. To allow for the per- forations, in accordance with the model theoretical results for perforated plates were obtained, but including the modified reduction factor (1 - A / A0) applied to both strength and stiffness, to allow for the perforations on perforated plates. Typical compari- sons of theoretical and experimental results are shown by the study. Adequate ductility is exhibited by all panels. The panels have an aspect ratios, (b / d), equal to (300 / 300) and (450 / 300) with plate thickness, h, equal to 0.83 and $1.23 \mathrm{~mm}$. The diameter of the central circular openings, $\mathrm{D}$, varied from 0 to $150 \mathrm{~mm}$. Along one panel by applying equal and opposite loads, all panels were tested. Fig. 8 gives (a) Construction details of steel plate shear wall, and (b) Shear displacements of typical SPSW [8].
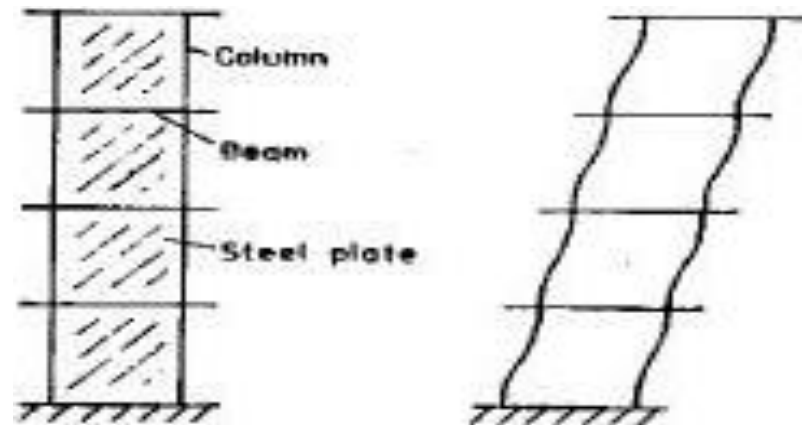

Fig. 8: Typical Steel Plate Shear Wall A) Construction Details of Steel Plate Shear Wall, B) Shear Displacements [8]

Again in 2000, Adam S. Lubell et al, in their study have shown that the steel plate shear walls exhibit many desirable characteris- tics for structures in areas of high seismic risk by the experimental and analytical components. These include stable hysteresis behav- ior and good displacement ductility capacity with desirable energy dissipation characteristics. For the engineering community to use in design, current guidelines for un - stiffened steel shear walls provide a good starting point. As primary LLRS for structures, SPSWs show good promise, with further improvements to the codified design methodologies and requirements, including those in areas of high seismic risk. During the experiments to observe accurately describe the behavior, a series of numerical models were generated for the three test specimens to assess the ability of current simplified analysis techniques. Fig. 9 shows (a) SPSW, and (b) Single panel of typical steel plate shear [2].
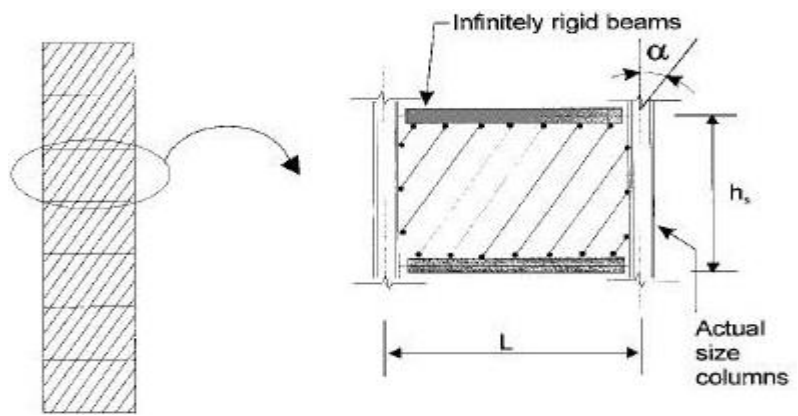

Fig. 9: Typical Steel Plate Shear A) Steel Plate Shear Wall, B) Single Pane [2].

\section{Conclusion}

For UN - stiffened SPSWs current guidelines for the engineering community provide a good starting point to use in design. SPSWs to the codified design methodologies and requirements, with further improvements for structures show good promise including in areas those of high seismic risk as a primary LLRS. To determine up to their ultimate capacity finite element analysis of SPSWs were conducted.

\section{References}

[1] A. Astaneh - ASL, "Steel plate shear walls", Proceedings, U.S. Japan Partnership for Advanced Steel Structures, U.S. - Japan Workshop on Seismic Fracture issues in Steel Structures, (San Francisco, 2000), pp. $1-12$.

[2] A. S. Lubell, H. G. L. Prion, C. E. Ventura and M. Rezai, "Unstiffened steel plate shear wall performance under cyclic loading", Journal of Structural Engineering, ASCE, Vol. 126, No. 4, (2000), pp. $453-460$. 
[3] M. Elgaaly, and Y. Liu, "Analysis of thin - steel plate shear walls", Journal of Structural Engineering, ASCE, Vol. 123, No. 11, (1997), pp. $1487-1496$.

[4] M. Elgaaly, V. Caccese, and C. Du, "Postbuckling behavior of steel

[5] - plate shear walls under cyclic loads", Journal of Structural Engineering, ASCE, Vol. 119, No. 2, (1993), pp. 588 - 605.

[6] R. G. Driver, G. L. Kulak, A. E. Elwi, and D. J. L. Kennedy, "FE and simplified models of steel - plate shear wall", Journal of Structural Engineering, ASCE, Vol. 124, No. 2, (1998), pp. 121 - 130.

[7] R. G. Driver, G. L. Kulak, D. J. L. Kennedy and A. E. Elwi, "Seismic performance of steel plate shear walls based on a large - scale multi - storey test', Proceedings, Eleventh World Conference on Earthquake Engineering, (Mexico, 1996), pp. $1-8$

[8] R. G. Driver, G. L. Kulak, D. J. L. Kennedy, and A. E. Elwi, "Cyclic Test of four - story steel - plate shear wall”, Journal of Structural Engineering, ASCE, Vol. 124, No. 2, 1998, pp. 112 - 120.

[9] S. Sabouri - Ghomi, "Reduction of strength and stiffness and hysteretic characteristics of perforated thin steel plate shear walls", Proceedings, Twelfth World Conference on Earthquake Engineering, (New Zealand, 2000), pp. $1-8$.

[10] V. Caccese, M. Elgaaly, and R. Chen, "Experimental study of thin steel - plate shear walls under cyclic load", Journal of Structural Engineering, ASCE, Vol. 119, No. 2, 1993, pp. 573 - 587. 